\title{
MEAN-VARIANCE VERSUS MEAN-EXPECTED SHORTFALL MODELS: AN APPLICATION TO WHEAT VARIETY SELECTION
}

\author{
KUNLAPATH SUKCHAROEN* \\ Department of Agricultural Economics, Texas A\&M University, College Station, Texas \\ DAVID LEATHAM \\ Department of Agricultural Economics, Texas AઐM University, College Station, Texas
}

\begin{abstract}
One of the most popular risk management strategies for wheat producers is varietal diversification. Previous studies proposed a mean-variance model as a tool to optimally select wheat varieties. However, this study suggests that the mean-expected shortfall (ES) model (which is based on a downside risk measure) may be a better tool because variance is not a correct risk measure when the distribution of wheat variety yields is multivariate nonnormal. Results based on data from Texas Blacklands confirm our conjecture that the mean-ES framework performs better in term of selecting wheat varieties than the mean-variance method.
\end{abstract}

Keywords. Conditional value at risk, expected shortfall, portfolio theory, wheat variety selection

JEL Classifications. C15, G11, Q12, Q15

\section{Introduction}

It is alarming that recent climate changes (especially, the continued changes in frequency and intensity of high-temperature events) could lead to severe reduction in wheat production and higher variability in wheat yields (Gourdji et al., 2013; Lobell, Sibley, and Ortiz-Monasterio, 2012; Tack, Barkley, and Nalley, 2014, 2015a; Tubiello et al., 2002). Among a variety of risk management strategies, diversification has been perceived as an effective risk management tool for mitigating yield risk caused by diverse growing conditions and unpredictable climate (Barry and Ellinger, 2012; Boggess, Anaman, and Hanson, 1985; Bradshaw, Dolan, and Smit, 2004; Knutson et al., 1998; Sonka and Patrick, 1984). For agriculture, diversification may take several forms. For example, the producers may increase the number of farm locations (i.e., geographic diversification) to reduce risk associated with location-specific weather conditions and with stochastic price (or demand) shocks to local

The authors would like to thank two anonymous reviewers for their valuable comments.

*Corresponding author: e-mail: kunlapath@tamu.edu 
markets. Another method of diversification is to broaden the existing marketable activities by, for example, adding value to existing production (i.e., enterprise diversification) to produce better cash flow for the business. Diversification may also take the form of growing more than one field crop (i.e., crop diversification) or more than one variety of a particular crop (i.e., varietal diversification).

Of these many forms of agricultural diversification, varietal diversification seems to be the most cost-effective method for wheat producers to manage yield risk. Moreover, recent studies by Tack, Barkley, and Nalley (2014) and Tack et al. (2015) show that warming and drought affect production of different wheat varieties in different ways. Therefore, planting more than one wheat variety each year potentially forms a natural insurance against the risk associated with yield loss from changing climate and growing conditions. The question is how to determine the optimal mix of wheat varieties. Portfolio theory, initially developed by Markowitz (1952), provides a unique optimal (at least in-sample) solution given the producers' chosen level of risk. In particular, the theory suggests that wheat varietal diversification could reduce yield risk and, consequently, income risk, through less-than-unit correlations among yields of different wheat varieties. To determine the optimal allocation of land to the various wheat varieties, the analysis often proceeds by constructing a traditional mean-variance frontier. In crop variety selection, several studies applied the mean-variance framework and showed that farm profitability could be enhanced through mean-variance optimization (Barkley, Peterson, and Shroyer, 2010; Mortenson et al., 2012; Nalley and Barkley, 2010; Nalley et al., 2009).

A major drawback of the standard mean-variance analysis is that it uses variance, which treats both upside and downside risk as the same, as the risk measure. Because the producers often consider the upside risk to be favorable, the use of variance seems to be inappropriate. The only case in which upside and downside risk are the same, and, thus, variance is a correct measure of risk, is when crop yields or profits are normally distributed. However, in reality, agricultural yields have been shown to be nonnormal (Atwood, Shaik, and Watts, 2003; Day, 1965; Gallagher, 1987; Ramirez, Misra, and Field, 2003). Given that the producers are only concerned with the downside risk, some studies used expected shortfall (ES) or conditional value at risk (VaR), which measures the risk of the actual yield being far below the expected yield (i.e., the downside risk), as the risk measure (for applications of ES in agriculture, see, e.g., Larsen, Leatham, and Sukcharoen, 2015; Strauss et al., 2009; Zylstra, Kilmer, and Uryasev, 2003). One could then use a mean-ES model, instead of the mean-variance model, to determine an optimal proportion of each crop variety to be planted.

Even though researchers are well aware that crop yields may not be normally distributed and that wheat producers are particularly concerned with the downside risk, to our best knowledge, none of the existing studies have applied the mean-ES model to the wheat variety selection problem. This study is, therefore, the first study to explore the potential benefits of the mean-ES approach 
as a technique to select wheat varieties. Particularly, we compare optimal wheat variety mixes obtained from the mean-variance framework with those from the mean-ES model and then examine potential gains from applying the two portfolio optimization methods to wheat variety selection. Understanding how different optimization models perform in the context of wheat variety selection provides useful insights for designing optimal mixes of wheat varieties to plant. In addition, our study adds to earlier studies on wheat variety selection by applying the methods to a different data set. Although the previous studies applied portfolio theory to wheat variety selection decisions in Kansas (Barkley, Peterson, and Shroyer, 2010), Colorado (Mortenson et al., 2012), the Yaqui Valley of northwestern Mexico (Nalley and Barkley, 2010), and the Texas High Plains (Park et al., 2012), we consider the wheat selection problem in Texas Blacklands. The location is chosen based on data availability and the lack of previous research. Last but not least, unlike previous studies that evaluate the performance of the optimization models on the period over which the model is estimated (i.e., the optimization or in-sample period), the present study looks at how well the models perform the year after the estimation period. This is a better way to evaluate the performance of optimization strategies because, in reality, wheat producers must make decisions regarding which varieties to be planted next year before the next-year yield data exist.

This research should provide useful information for agricultural producers who aim at improving variety selection and developing a new strategy to cope with a hotter climate. ${ }^{1}$ The remainder of this study proceeds as follows: Section 2 describes the mean-variance and mean-ES optimization methods. Section 3 is then devoted to describing the data. Section 4 discusses the results of portfolio optimizations. Finally, Section 5 summarizes and concludes.

\section{Optimization Methods}

This study focuses on a single-period wheat variety selection problem because wheat producers can change the varieties planted each year. To identify the optimal mix of wheat varieties, previous studies applied the standard meanvariance optimization framework. However, the choice of variance as a risk measure is only appropriate when wheat yields are normally distributed. Given the possibility that wheat yields are nonnormally distributed, a downside risk measure such as ES is preferable.

Another measure of downside risk is VaR, which also addresses the said limitation of variance as a risk measure. Nonetheless, for nonnormal distributions, VaR does not possess the subadditivity property, one of the

\footnotetext{
1 We thank an anonymous referee for pointing out the latter contribution. Also, Tack et al. (2015) provide a more detailed discussion regarding the need for decision-theoretic models to guide adaptation decisions.
} 
properties that a risk measure should have (for more details, see Artzner et al., 1999). Without the subadditivity property, the VaR of a portfolio of two varieties may be greater than that of each individual variety, suggesting that varietal diversification should be discouraged. In this case, VaR is not convex (for definition of convexity, see Rockafellar and Uryasev, 2000), making it difficult to solve the optimization problem because multiple local solutions may exist (Mausser and Rosen, 1998). This implies that when the underlying distributions of crop yields are nonnormal, the portfolio optimization problem based on VaR should be avoided. An alternative to the VaR is the portfolio optimization based on ES, which is a downside risk measure that has been found to be subadditive and convex even without the normality assumption (Rockafellar and Uryasev, 2000). Therefore, when wheat yields are nonnormally distributed, the mean-ES model is preferable to the mean-variance model and the mean-VaR model for the problem of wheat variety selection.

In the following sections, we first provide an overview of the traditional meanvariance model, which serves as a benchmark in our analysis. We then describe the mean-ES model and discuss our data-smoothing and simulation procedure used to calculate ES.

\subsection{The Mean-Variance Model}

The first model used in this study to derive efficient portfolios of wheat varieties is the traditional mean-variance model developed by Markowitz (1952). Similar to Barkley, Peterson, and Shroyer (2010), Nalley and Barkley (2010), Nalley et al. (2009), and Mortenson et al. (2012), it is assumed that a wheat producer's objective is to choose the optimal share of total acres allocated to each wheat variety. Let $\alpha_{i}$ be the share of total acres allocated to variety $i$, where $i=1, \ldots, n$; $y_{i}$ be the yield mean of variety $i$; and $\sigma_{i j}$ be the covariance of yields for varieties $i$ and $j$. Then, the portfolio yield (i.e., the weighted average yield) is defined as

$$
Y=\sum_{i} \alpha_{i} y_{i}
$$

and the portfolio variance (i.e., total farm variety yield variance) is defined as

$$
V=\sum_{i} \sum_{j} \alpha_{i} \alpha_{j} \sigma_{i j}
$$

The mean-variance analysis selects the optimal mix of wheat varieties by minimizing the portfolio variance subject to the constraints of portfolio yield being equal to the (positive) target yield of $\sum_{i} \alpha_{i}=1$ and of nonnegative share of wheat variety $i$. Mathematically, this optimization problem is formulated as follows:

$$
\min _{\alpha_{1}, \ldots, \alpha_{n}} \sum_{i} \sum_{j} \alpha_{i} \alpha_{j} \sigma_{i j}
$$


subject to:

$$
\begin{aligned}
\sum_{i} \alpha_{i} y_{i} & =\lambda \\
\sum_{i} \alpha_{i} & =1 \\
\alpha_{i} & \geq 0 \text { for all } i .
\end{aligned}
$$

The solution to this problem is given as $\alpha=\left(\alpha_{1}, \ldots, \alpha_{n}\right)$ for each $\lambda$. From this, we attain an optimized portfolio variance $V$ for each $\lambda$, from which we obtain the mean-variance efficiency frontier. The nonlinear mean-variance model is programmed in Microsoft Excel and solved using the Microsoft Excel Solver tool.

\subsection{The Mean-Expected Shortfall Model}

The second model used to estimate the optimal mix of wheat varieties is the mean-ES, or mean-ES model. The only difference between the mean-ES model and the traditional mean-variance model is that the mean-ES model minimizes the ES instead of the portfolio variance.

In this study, ES is defined as

$$
E S_{\beta}=-E[Y \mid Y \leq q],
$$

where $q$ is the $\beta$ th percentile of the portfolio yield distribution (i.e., $\operatorname{Pr}[Y \leq q]=$ $\beta$ ). This study considers the parameter $\beta$ equal to $0.1,0.05$, and 0.01 . In words, ES is the expected portfolio yield loss; it represents the negative of the mean of portfolio yields that are lower than the $\beta$ th percentile. We calculate ESs at the $10 \%, 5 \%$, and $1 \%$ levels using a semiparametric simulation method to be discussed in the next subsection.

Let $\tilde{y}_{i, s}$ be the simulated yield of variety $i$ for the $s$ th iteration (with $s=1, \ldots, 10,000)$. Using the same notation as given previously, portfolio optimization based on ES by a simulation-based method is formulated as follows:

$$
\min _{\alpha_{1}, \ldots, \alpha_{n}}-E\left[\sum_{i} \alpha_{i} \tilde{y}_{i, s} \mid \sum_{i} \alpha_{i} \tilde{y}_{i, s} \leq q\right],
$$

subject to:

$$
\begin{aligned}
\left(\frac{1}{S}\right) \sum_{s} \sum_{i} \alpha_{i} \tilde{y}_{i, s} & =\phi \\
\sum_{i} \alpha_{i} & =1 \\
\alpha_{i} & \geq 0 \text { for all } i .
\end{aligned}
$$


The solution to this problem is given as $\alpha=\left(\alpha_{1}, \ldots, \alpha_{n}\right)$ for each $\phi$. From this, we attain an optimized portfolio ES, $E S_{\beta}$, for each $\phi$, from which we obtain the mean-ES efficiency frontier. The problem of minimizing portfolio ES is solved using the Microsoft Excel Solver tool. We also use Matlab Financial Toolbox to calculate the mean-ES efficient portfolios to validate the results obtained by the Excel Solver program.

\subsection{Data-Smoothing and Simulation Procedure}

There are three main methods for calculating ES: the nonparametric historical simulation method, the semiparametric simulation method, and the parametric method. On the one hand, the historical simulation method does not require any parametric assumption about the distribution of wheat yields. However, the method assumes stationarity (i.e., future yields will be similar to the past yields). This is a very strong assumption, especially when only limited historical observations are available. Given the shortness of relevant historical data of wheat variety yields, the historical simulation method is not appropriate. On the other hand, the parametric method assumes that wheat variety yields follow a particular multivariate probability distribution. The mean-variance approach relies on the use of a multivariate normal distribution. If yields are assumed to be normally distributed, both mean-variance and mean-ES models lead to the same optimal mixes of wheat varieties. In addition, as mentioned previously, several studies find that some crop yields are not normally distributed. Therefore, the mean-ES analysis in this study takes a nonnormal characteristic of wheat variety yields into consideration. Still, the parametric simulation method is inherently subject to misspecification of the distribution. Finally, the semiparametric simulation method is a hybrid of the nonparametric and parametric approaches and, thus, offers more flexibility in term of modeling the distributions for random variables. This study, therefore, uses the semiparametric simulation method to simulate the distributions of wheat variety yields and compute the corresponding value of portfolio ES.

To deal with sparse (limited) data, we use the multivariate kernel density estimation (MVKDE) procedure ${ }^{2}$ proposed by Richardson, Lien, and Hardaker (2006) to smooth out irregularities in the sparse data and fit a multivariate probability distribution. The MVKDE method can be briefly summarized in two steps. The first step is to use a kernel density estimator (KDE) to construct a smooth, continuous probability density function for each variable (i.e., each yield variety) in the system. Before estimating the kernel distributions, we separate the stochastic and deterministic components of the random variables. Because yield is often a linear function of trend, we use an ordinary least squares (OLS) regression on a linear trend to identify the nonrandom components of each

2 Other studies in agriculture using the MVKDE procedure include, for example, Lien et al. (2009), Lien et al. (2011), and Ribera et al. (2007). 
random variable. When the linear trend is not statistically significant, we use the simple yield means to remove the nonrandom components.

For each historical detrended (or demeaned) variety yield series, we consider the following 11 different kernel density functions: Cauchy, cosinus, double exponential, Epanechnikov, Gaussian, Parzen, quartic, semiparametric normal, triangle, triweight, and uniform. The most appropriate kernel density function for each variety is selected based on the root-mean-square error (RMSE) of the differences between the cumulative probabilities of the histogram and those of the particular kernel function. The kernel function with the smallest RMSE is chosen. In a standard cumulative distribution function, the cumulative probabilities of the minimum and maximum yields are assumed to be equal to 0 and 1 , respectively. This implies that the probability of observing the historical minimum and maximum yields are equal to 0 . Following Richardson, Klose, and Gray (2000), we correct this problem by adding two pseudoobservations: pseudominimum and pseudomaximum. The pseudominimum (maximum) is calculated by multiplying the actual detrended or demeaned minimum (maximum) yield and 1.000001. The cumulative probabilities of the pseudominimum and pseudomaximum are then set to be equal to 0 and 1 , respectively.

The second step is to simulate the chosen KDE distributions from the previous step as a multivariate distribution using the multivariate empirical (MVE) approach outlined in details by Richardson, Klose, and Gray (2000). The approach is only briefly described here. The starting point is to model dependencies among wheat variety yields. Copulas are the most general method for this task. Given the shortness of the data, the choice of copulas is more or less limited to the Gaussian (or normal) copula. The only parameter matrix needed for the Gaussian copula is the correlation matrix, $P_{n \times n}$, calculated using actual historical detrended (or demeaned) variety yield series. The correlation matrix is then factored by the Choleski decomposition. The factored correlation matrix, $R_{n \times n}$, is calculated such that $P=R R^{\prime}$. A vector of correlated standard normal deviates, $C_{n \times 1}$, is simulated by multiplying the factored correlation matrix, $R_{n \times n}$, and a vector of independent standard normal deviates, $Z_{n \times 1}$ (i.e., $C=R Z$ ). Each element in the vector $C$ is then transformed to a correlated uniform standard deviate, using the error function (i.e., the integral of the standard normal distribution from negative infinity to $C_{i}$ ). Given the vector of correlated uniform standard deviates, $U_{n \times 1}$, a vector of simulated MVKDE, $K_{n \times 1}$, is then generated using the inverse transform function of an empirical distribution defined using the KDE distribution for each variety $i$. For each of the 10,000 iterations, the simulated wheat variety yields are generated using:

$$
\tilde{y}_{i, s}=\hat{y}_{i, s}+K_{i, s}
$$

where $\tilde{y}_{i, s}$ is the simulated yield of variety $i$ for the $s$ th iteration (with $s=$ $1, \ldots, 10,000) ; \hat{y}_{i}$ is the deterministic component of yield of variety $i$; and $K_{i, s}$ 
is the simulated MVKDE for variety $i$ for the $s$ th iteration. Given the simulated variety yields, portfolio ESs are then computed using equation (7). Parameters of kernel density functions and MVE yield distribution can be estimated using Matlab or R.

\section{Data}

Data on dryland hard wheat yields for various varieties planted in Texas Blacklands ${ }^{3}$ are available from Texas A\&M University publications on Texas Wheat Variety Trial results (Texas A\&M AgriLife Extension Service, Texas A\&M AgriLife Research, and AgriPro Wheat, 2008, 2009, 2010; Texas A\&M AgriLife Extension Service, Texas A\&M AgriLife Research, and Syngenta Wheat, 2011, 2012, 2013, 2014; Texas Cooperative Extension and Texas Agricultural Experiment Station, 2005, 2006, 2007). As pointed out by an anonymous referee, there exists a gap between in-trial (or experimental) and on-farm (or actual) yields. ${ }^{4}$ In other words, the in-trial yields might not fully reflect on-farm performance, and, therefore, the findings of this study might be biased as a result of the unavoidable yield-gap problem. However, the upside of the trial data is that they provide valuable information that might not be otherwise available, including data for new wheat varieties. ${ }^{5}$ In addition, a major driver of the gap between in-trial and on-farm wheat yields is the difference in on-farm production decisions, not producers' variety selection decisions (Tack, Barkley, and Nalley, $2015 b)$. Also, the in-trial relative yields are very likely to be similar to the onfarm relative yields (Brennan, 1984). Therefore, the analysis based on the trial data is likely to provide reliable yield comparisons across varieties.

The wheat varieties considered for the analysis must satisfy the two criteria: (1) the variety appears within the publication for the year 2014; and (2) observations of the variety are available for at least five consecutive years just before the year $2014^{6}$ (i.e., for the years 2008-2013) for the estimations of the correlation matrix and the multivariate probability distribution. Even though the data are available since the year 2005, the initial year of 2008 is selected to maximize the number of wheat varieties satisfying the previously discussed criteria. Accordingly, a total of 10 wheat varieties (Coronado, Duster, Fannin, Greer, Jackpot, TAM 111,

\footnotetext{
${ }^{3}$ We also consider dryland hard wheat yield data for the other two locations in Texas: Texas High Plains and Texas Rolling Plains. However, for the period under consideration, the correlations between any two wheat varieties for the two locations are extremely high (higher than 0.95 for almost all the cases). The extremely high correlations suggest that the different yield varieties should not be treated as separate wheat classes. This makes the analysis in these locations uninteresting. Therefore, the study focuses only on the case of Texas Blacklands.

${ }^{4}$ This is particularly because of diverse environmental conditions and different management practices.

${ }^{5}$ It should be noted that a sufficient number of observations for these data are required for the calculation of mean, variance, and ES.

${ }^{6}$ Given the shortness of available historical data, we only set aside the data for the year 2014 for evaluating the performance of the mean-variance and mean-ES models.
} 


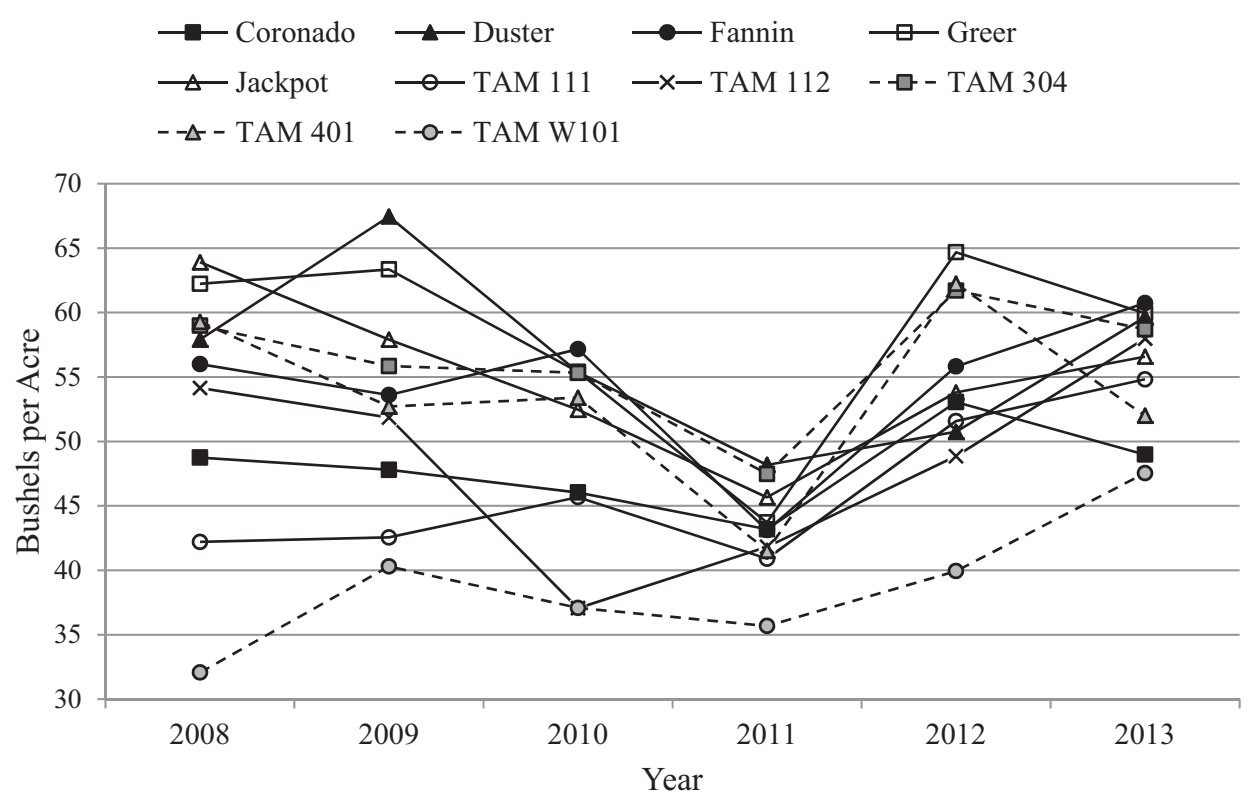

Figure 1. Historical Yields for the Selected Wheat Varieties, 2008-2013

TAM 112, TAM 304, TAM 401, and TAM W101) are included in the analysis. ${ }^{7}$ Figure 1 illustrates historical yields for the 10 selected wheat varieties for the years 2008-2013. TAM W101 constantly produces the lowest yield, whereas Duster, Greer, and TAM 304 produce relatively high yields over time. There is, however, no all-time best wheat variety, which provides a good reason for varietal diversification.

Table 1 reports summary statistics of yields for the selected wheat varieties for the time period 2008-2013 (the optimization or in-sample period). Greer has the highest average yield ( 58.22 bushels per acre), followed by Duster ( 56.55 bushels per acre) and TAM 304 (56.34 bushels per acre). TAM W101 has the lowest average yield (38.77 bushels per acre), followed by TAM 111 (46.29 bushels per acre) and Coronado (47.97 bushels per acre). The most volatile varieties are TAM 112 (7.86 bushels per acre), Greer (7.81 bushels per acre), and TAM 401 (7.16 bushels per acre); whereas the least volatile varieties are Coronado (3.29

${ }^{7}$ For each year, all the 10 varieties of hard wheat were planted at multiple locations within Texas Blacklands, including Ellis County (for the years 2008, 2010, 2011, 2012, 2013, and 2014), FarmersVille (for the year 2014), Grayson County (for the year 2010), Hillsboro (for the years 2008, 2009, 2010, 2011, 2013, and 2014), Lamar County (for the years 2012, 2013, and 2014), McGregor (for the years 2008, 2009, 2010, 2011, 2012, and 2014), Muenster (for the years 2010, 2011, 2012, and 2013), and Prosper (for the years 2008, 2011, 2012, and 2013). Even though the locations planted varied from one year to another, in each year all the wheat varieties were planted at the same locations. In addition, the production and management practices were held constant across different locations. Therefore, the yield variation across varieties is mainly driven by the year-to-year weather variation. 
Table 1. Summary Statistics of In-Sample Yields for the Selected Wheat Varieties, 2008-2013

\begin{tabular}{lcllll}
\hline \hline Variety & Mean & $\begin{array}{l}\text { Standard } \\
\text { Deviation }\end{array}$ & $\begin{array}{l}\text { Coefficient of } \\
\text { Variation }(\%)\end{array}$ & Minimum & Maximum \\
\hline Coronado & 47.97 & 3.29 & 6.87 & 43.18 & 53.06 \\
Duster & 56.55 & 6.86 & 12.13 & 48.18 & 67.45 \\
Fannin & 54.40 & 6.01 & 11.05 & 43.10 & 60.74 \\
Greer & 58.22 & 7.81 & 13.42 & 43.72 & 64.68 \\
Jackpot & 55.05 & 6.09 & 11.06 & 45.66 & 63.90 \\
TAM 111 & 46.29 & 5.67 & 12.25 & 40.90 & 54.82 \\
TAM 112 & 48.62 & 7.86 & 16.16 & 37.06 & 57.98 \\
TAM 304 & 56.34 & 4.92 & 8.73 & 47.48 & 61.70 \\
TAM 401 & 53.52 & 7.16 & 13.37 & 41.52 & 62.24 \\
TAM W101 & 38.77 & 5.25 & 13.55 & 32.07 & 47.54 \\
\hline \hline
\end{tabular}

Table 2. 2014 Wheat Variety Yields and 2014 Actual Allocation of Wheat Varieties Planted in Texas Blacklands

\begin{tabular}{llc}
\hline \hline Variety & 2014 Yields (bushels per acre) & 2014 Actual Allocation (\%) \\
\hline Coronado & 58.50 & 5.24 \\
Duster & 60.22 & 8.24 \\
Fannin & 61.73 & 39.33 \\
Greer & 65.48 & 7.12 \\
Jackpot & 62.90 & 0.75 \\
TAM 111 & 62.36 & 3.00 \\
TAM 112 & 56.70 & 0.00 \\
TAM 304 & 60.48 & 34.08 \\
TAM 401 & 60.84 & 2.25 \\
TAM W101 & 53.70 & 0.00 \\
\hline \hline
\end{tabular}

Notes: The " 2014 actual allocation" is defined as the percentage of total wheat acreage in Texas Blacklands planted with the 10 wheat varieties in 2014. Percents may not add to 100 because of rounding.

bushels per acre), TAM 304 (4.92 bushels per acre), and TAM W101 (5.25 bushels per acre). The coefficient of variation $(\mathrm{CV})$, defined as the ratio of the standard deviation to the mean, measures the relative variability of stochastic yields. A lower CV indicates a lower risk per unit of expected yield. The CV, reported in Table 1, indicates that TAM 112, TAM W101, and Greer are the riskiest wheat varieties to plant. Coronado, TAM 304, and Fannin are the safest varieties given their coefficients of variation.

Table 2 documents the wheat yield data for the year 2014 (to be used for evaluating the performance of optimization models). In 2014, the varieties are ranked from the highest to lowest yields as follows: Greer, Jackpot, TAM 111, Fannin, TAM 401, TAM 304, Duster, Coronado, TAM 112, and TAM W101. Table 2 also provides the 2014 actual allocation of wheat varieties planted in Texas Blacklands. In this study, we define the "2014 actual allocation" as 
the percentage of total wheat acreage in Texas Blacklands planted with the 10 wheat varieties in 2014. The 2014 actual planting data are obtained from the U.S. Department of Agriculture, National Agricultural Statistics Service (USDANASS, 2015) publication Percent of Wheat Acres Seeded for 2014. The report suggests that wheat producers do diversify the varieties planted on their farms. The top 3 wheat varieties planted in 2014 are Fannin $(39.33 \%)$, TAM 304 $(34.08 \%)$, and Duster $(8.24 \%)$. Two of the 10 varieties, TAM 112 and TAM W101, were not planted in Texas Blacklands in 2014. Recall that TAM 112 and TAM W101 have the highest coefficients of variation (see Table 1). Thus, it seems like the producers do avoid planting the varieties with high values of CV.

The concept of correlation lies at the heart of varietal diversification. Simply put, the objective of varietal diversification is to decrease yield risk by selecting a mix of wheat varieties whose productivities are less correlated. Table 3 reports pair-wise correlations among the selected wheat varieties for the period 20082013. The correlation coefficients range from -0.060 (Jackpot and TAM W101) to 0.941 (Coronado and TAM 304). As can be seen from Table 2, approximately $70 \%$ of total wheat acreage is allocated to Fannin and TAM 304. The correlation between Fannin and TAM 304 is 0.842 . Because the correlation between the two varieties is less than 1 , planting both varieties would offer diversification benefit to wheat producers. However, Fannin and TAM 304 are very highly correlated, so allocating a large proportion of land to only these two varieties may not be the best strategy. Put differently, further diversification benefits may be gained by choosing the better mix of wheat varieties. This study applies the mean-variance and mean-ES approaches to determine the optimal mix of wheat varieties. ${ }^{8}$ Results of detailed analysis on the optimal varietal allocations follow.

\section{Results}

In this section, we present results of the mean-variance and mean-ES optimizations. Data-smoothing and simulation results are also provided. We then compare the optimal allocations suggested by the various optimization models with the 2014 actual allocation of wheat varieties and examine potential gains (losses) from applying portfolio optimization methods to wheat variety selection with the 2014 actual allocation as the evaluation benchmark.

\subsection{Mean-Variance Optimization Results}

We first apply the mean-variance model to the in-sample data set (2008-2013) to derive the efficient mean-variance frontier. Figure 2 depicts the estimated

\footnotetext{
${ }^{8}$ As pointed out by an anonymous referee, it should be noted that instead of planting a portfolio of different wheat varieties on different plots in the field, wheat producers could mix the seeds from several varieties together and plant the mixtures of seeds across the field. In 2014, 3.2\% of wheat acres seeded in Texas Blacklands was planted to the mixtures of dryland hard wheat (USDA-NASS, 2015).
} 
Table 3. Correlations among the Selected Wheat Varieties, 2008-2013

\begin{tabular}{|c|c|c|c|c|c|c|c|c|c|c|}
\hline & Coronado & Duster & Fannin & Greer & Jackpot & TAM 111 & TAM 112 & TAM 304 & TAM 401 & TAM W101 \\
\hline Coronado & 1.00 & 0.13 & 0.64 & 0.87 & 0.51 & 0.64 & 0.54 & 0.94 & 0.89 & 0.32 \\
\hline Duster & & 1.00 & 0.47 & 0.57 & 0.65 & -0.02 & 0.52 & 0.29 & 0.18 & 0.31 \\
\hline Fannin & & & 1.00 & 0.76 & 0.65 & 0.69 & 0.47 & 0.84 & 0.69 & 0.48 \\
\hline Greer & & & & 1.00 & 0.79 & 0.42 & 0.61 & 0.93 & 0.88 & 0.26 \\
\hline Jackpot & & & & & 1.00 & 0.07 & 0.69 & 0.70 & 0.68 & -0.06 \\
\hline TAM 111 & & & & & & 1.00 & 0.40 & 0.63 & 0.38 & 0.81 \\
\hline TAM 112 & & & & & & & 1.00 & 0.56 & 0.36 & 0.44 \\
\hline TAM 304 & & & & & & & & 1.00 & 0.94 & 0.29 \\
\hline TAM 401 & & & & & & & & & 1.00 & -0.03 \\
\hline TAM W101 & & & & & & & & & & 1.00 \\
\hline
\end{tabular}




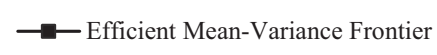

○ 2014 Actual Allocation with In-Sample Data

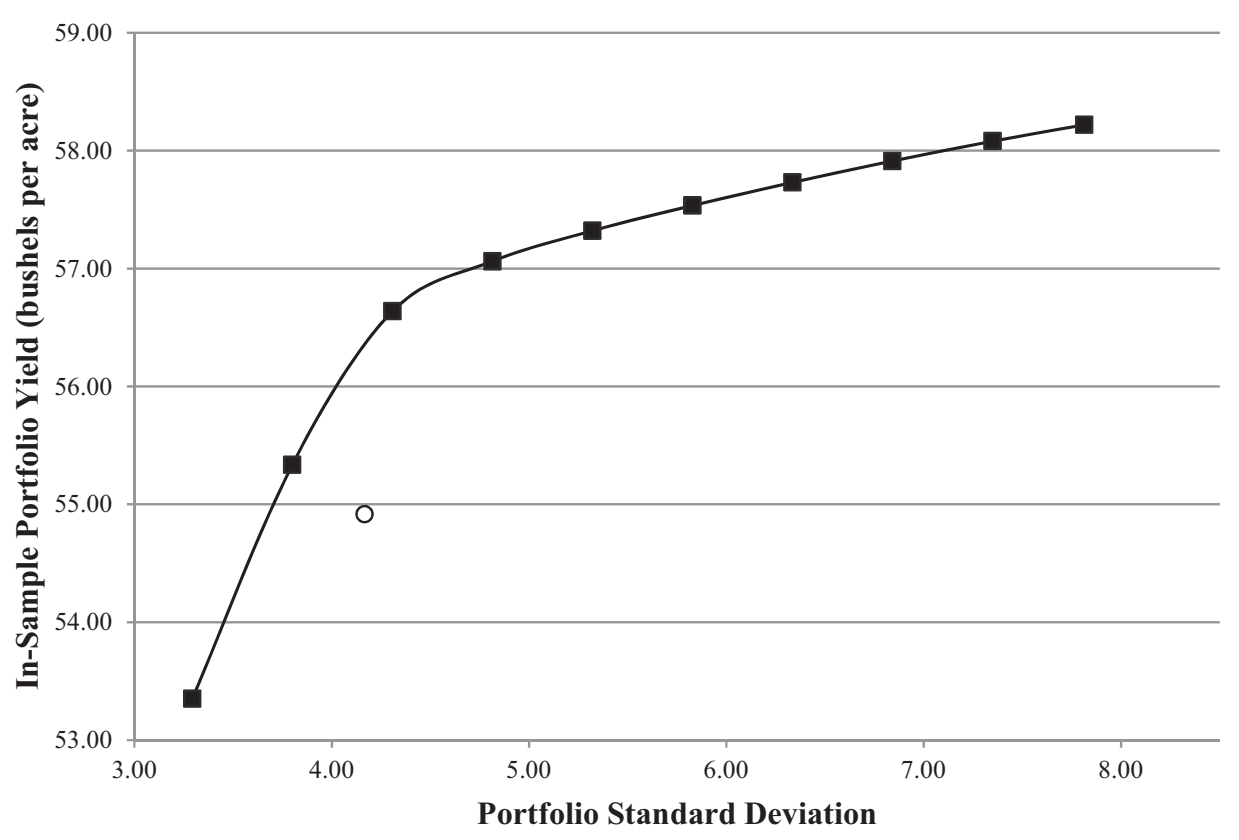

Figure 2. In-Sample Efficient Mean-Variance Frontier

mean-variance (standard deviation) frontier and shows where the 2014 actual allocation locates relative to the efficient frontier. For the in-sample analysis, the portfolio yield and standard deviation for the 2014 actual allocation are calculated from the in-sample variety yields and variances (not from the 2014 actual yields). The in-sample portfolio yield and standard deviation for the 2014 actual allocation are 54.92 bushels per acre and 4.17 bushels per acre, respectively. Results from the mean-variance model suggest that in-sample productivity (and therefore profitability) can be enhanced (or in-sample risk, as measured by variance or standard deviation, can be reduced) through varietal diversification. In other words, the 2014 actual allocation is not an optimal allocation for the period over which the model is estimated.

Table 4 illustrates the optimal allocations (the percentage of each variety to be planted) corresponding to the different points of the efficient mean-variance frontier (Figure 2). For the estimation period, Greer produces the highest average yield ( 58.22 bushels per acre). This highest portfolio yield constitutes the highest point on the efficient mean-variance frontier with the highest standard deviation (7.81 bushels per acre). The in-sample CV of the 2014 actual allocation is

The optimization approaches proposed in this study could be used in the selection of wheat varieties to include both in the portfolio and in the seed mixtures. 
Table 4. In-Sample Mean-Variance Portfolio Analysis, 2008-2013

\begin{tabular}{|c|c|c|}
\hline $\begin{array}{l}\text { Portfolio } \\
\text { Yield }\end{array}$ & $\begin{array}{l}\text { Portfolio } \\
\text { Standard Deviation }\end{array}$ & Optimal Mix of Wheat Varieties \\
\hline 53.35 & 3.29 & $\begin{array}{l}\text { 30.98\% Coronado, } 19.18 \% \text { Duster, } 6.88 \% \text { Fannin, } 10.00 \% \\
\text { Jackpot, } 1.72 \% \text { TAM } 111,31.24 \% \text { TAM } 304\end{array}$ \\
\hline 55.34 & 3.80 & $\begin{array}{l}\text { 9.15\% Coronado, } 22.54 \% \text { Duster, } 8.87 \% \text { Fannin, } 2.07 \% \text { Greer, } \\
\text { 11.75\% Jackpot, } 45.62 \% \text { TAM } 304\end{array}$ \\
\hline 56.64 & 4.31 & $27.22 \%$ Duster, $15.01 \%$ Greer, 3.12\% Jackpot, $54.65 \%$ TAM 304 \\
\hline 57.06 & 4.81 & $24.36 \%$ Duster, $35.76 \%$ Greer, $39.88 \%$ TAM 304 \\
\hline 57.32 & 5.32 & $21.71 \%$ Duster, $49.79 \%$ Greer, $28.50 \%$ TAM 304 \\
\hline 57.54 & 5.83 & $19.49 \%$ Duster, $61.48 \%$ Greer, $19.03 \%$ TAM 304 \\
\hline 57.73 & 6.33 & $17.50 \%$ Duster, $72.03 \%$ Greer, $10.47 \%$ TAM 304 \\
\hline 57.91 & 6.84 & $15.65 \%$ Duster, $81.89 \%$ Greer, $2.46 \%$ TAM 304 \\
\hline 58.08 & 7.35 & $8.31 \%$ Duster, $91.69 \%$ Greer \\
\hline 58.22 & 7.81 & $100 \%$ Greer \\
\hline
\end{tabular}

Note: Percents may not add to 100 because of rounding.

$7.59 \%$ (calculated as 4.17/54.92). For wheat producers interested in increasing (at least, in-sample) portfolio yield while holding the relative variability constant, a combination of $27.22 \%$ Duster, $15.01 \%$ Greer, 3.12\% Jackpot, and $54.65 \%$ TAM 304 would result in an average historical yield of 56.64 bushels per acre. This portfolio produces a higher average yield (56.64 vs. 54.92 bushels per acre), but with the CV of $7.60 \%$ (calculated as $4.31 / 56.64$ ), which is just a little bit higher than the CV of the 2014 actual allocation (7.59\%). As expected, similar to the previous studies (Barkley, Peterson, and Shroyer, 2010; Mortenson et al., 2012; Nalley and Barkley, 2010; Nalley et al., 2009), in-sample farm profitability could be enhanced through the mean-variance optimization. It is, nonetheless, still ambiguous about how well the mean-variance strategy performs relative to the 2014 actual allocation the year after the in-sample estimation period.

\subsection{Mean-Expected Shortfall Optimization Results}

For the mean-ES analysis, the in-sample data are fitted to a multivariate probability distribution using the MVKDE procedure discussed previously. Results from an OLS regression on a linear trend fail to indicate a statistically significant trend component at the $5 \%$ level for all variety yield data. ${ }^{9}$ Therefore, the mean of each variety yield is used as the nonrandom component of each

\footnotetext{
9 To elaborate, for each wheat variety $i$, we regress the yield $y_{i}$ on an intercept and a linear trend. We then test the null hypothesis of no linear trend using the Student's $t$-test based on both homoskedasticityonly and heteroskedasticity-consistent standard errors. With the homoskedasticity-only standard errors, the null hypothesis cannot be rejected at the $5 \%$ level for any of the series. With the heteroskedasticityconsistent standard errors, the null hypothesis can be rejected at the $5 \%$ level only for the cases of TAM 111 and TAM W101. For simplicity and consistency of the analysis, we use the mean of each variety yield as the nonrandom component for all varieties. The regression results are available upon request.
} 
Table 5. In-Sample Mean-Expected Shortfall Portfolio Analysis at the 10\% Level, 2008-2013

\begin{tabular}{lll}
\hline \hline Portfolio Simulated Yield & Portfolio Expected Shortfall $(10 \%)$ & Optimal Mix of Wheat Varieties \\
\hline 56.73 & -48.47 & $84.61 \%$ Duster, 15.39\% TAM 304 \\
56.78 & -48.45 & $89.96 \%$ Duster, 10.04\% TAM 304 \\
56.83 & -48.38 & $95.32 \%$ Duster, 4.68\% TAM 304 \\
56.88 & -48.21 & $97.95 \%$ Duster, 2.05\% Greer \\
56.94 & -47.56 & $81.63 \%$ Duster, 18.37\% Greer \\
56.99 & -46.86 & $65.30 \%$ Duster, 34.70\% Greer \\
57.04 & -46.14 & $48.98 \%$ Duster, 51.02\% Greer \\
57.10 & -45.39 & $32.65 \%$ Duster, $67.35 \%$ Greer \\
57.15 & -44.62 & $16.33 \%$ Duster, 83.67\% Greer \\
57.20 & -43.79 & $100 \%$ Greer \\
\hline \hline
\end{tabular}

Note: Percents may not add to 100 because of rounding.

stochastic yield. That is, all random yields are demeaned. For each demeaned yield series, the Parzen kernel is selected, based on the minimum RMSE criterion, to smooth out irregularities in the sparse data. ${ }^{10}$ The estimated Parzen kernel functions and the correlation matrix ${ }^{11}$ (Table 3 ) are then used to simulate the random (demeaned) yields for 10,000 iterations. Given that the trend is not statistically significant, the historical yield means are used as the projected yields (the deterministic component of yields in equation 12) to simulate the wheat variety yields.

We perform two types of validation tests on the simulated random variables to check whether the simulated yields statistically reproduce the historical yield means and correlation.

First, the Hotelling's T-squared test (Johnson and Wichern, 2002) is used to test if the two sets of means (simulated and historical means) are equal. At the $95 \%$ confidence level, the mean vector of the simulated data is not statistically different from the mean vector of the historical data. Second, Student's $t$-tests are used to test if the simulated yields are appropriately correlated. At the 99\% confidence level, the correlation coefficients in the simulated data are not statistically different from their respective historical correlation coefficients. ${ }^{12}$

Given the simulated yields of the 10 wheat varieties, optimal portfolios are derived by solving the mean-ES optimization problem discussed previously. Figure 3 displays the efficient mean-ES portfolios at the 10\% level, and Table 5 reports the optimal land allocations to the various wheat varieties corresponding

10 The selection results of the kernel functions are available from the authors upon request.

11 Note that the correlation matrix here is calculated using the demeaned yields. Therefore, the resulting matrix is the same as the correlation matrix calculated using the original yield data reported in Table 3.

12 The statistics for model validation tests are not reported here to conserve space but are available from the authors upon request. 


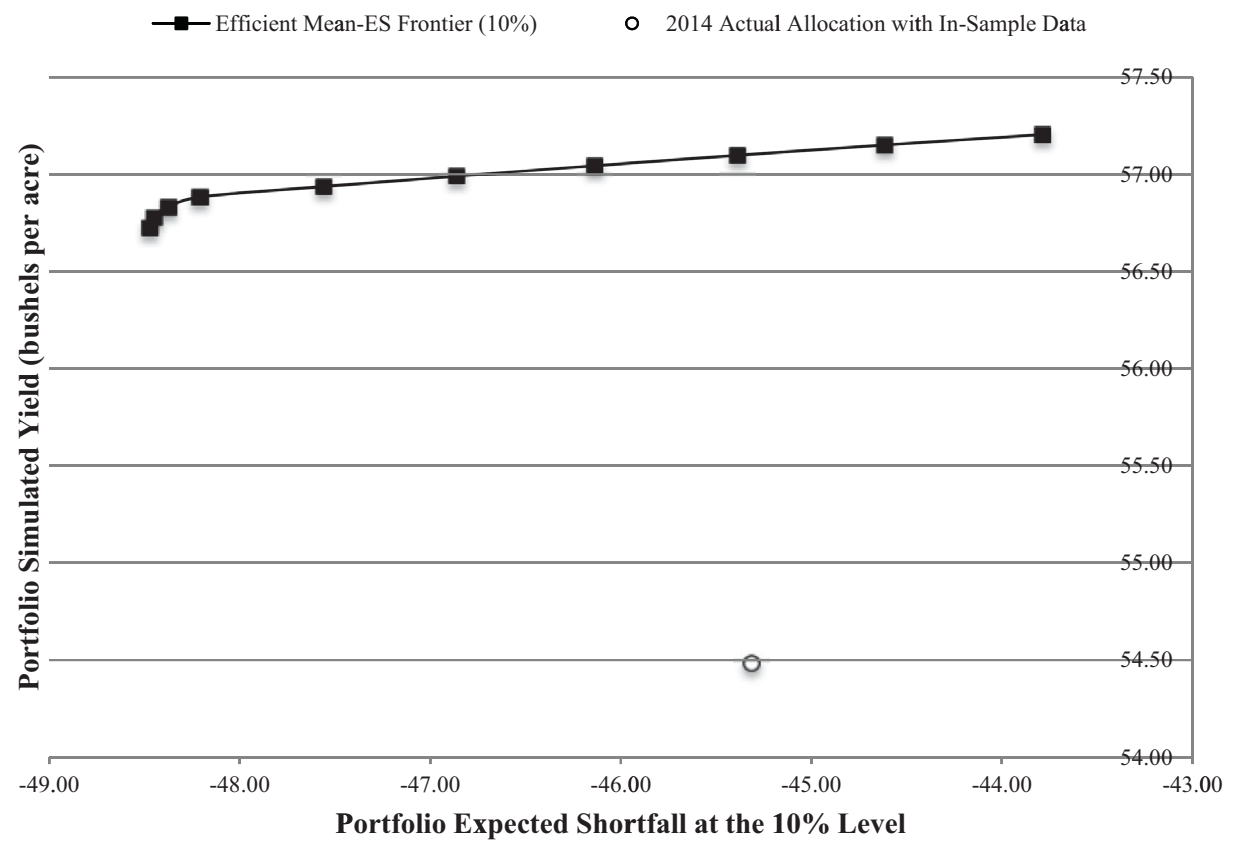

Figure 3. In-Sample Efficient Mean-Expected Shortfall (ES) Frontier (at the 10\% level)

to the different points of the efficient mean-ES frontier at the $10 \%$ level. ${ }^{13}$ Figure 3 also displays where the 2014 actual allocation locates relative to the frontier. The portfolio yield and ES at the $10 \%$ level for the 2014 actual allocation (54.48 bushels per acre for the former and -45.32 bushels per acre ${ }^{14}$ for the latter) are computed from the simulated yields. Obviously, the mean-ES model suggests that in-sample the 2014 actual allocation is not an optimal mix of wheat varieties, because such an allocation is not on the efficient mean-ES frontier.

13 Notably, the mean-ES results at the $5 \%$ and $1 \%$ levels are very similar to those obtained at the $10 \%$ level and are not reported here to conserve space. The results are, however, available from the authors upon request.

14 The negative number does not mean that the wheat yield is negative (which is obviously not possible). Recall that ES at the $10 \%$ level represents the negative of the mean of portfolio yields that are lower than the 10th percentile. As an illustration, consider the following two distributions of portfolio yields. The expected yields given that the yields are less than the 10th percentile (assumed to be 46 bushels per acre for both distributions) are 44 bushels per acre for the first distribution and 38 bushels per acre for the second distribution. A wheat producer would prefer the first distribution because at the $10 \%$ chance the first distribution produces, on average, 44 bushels per acre, whereas the second portfolio produces only, on average, 38 bushels per acre. For a risk measure, a higher number should imply higher risk. By definition, ESs at the $10 \%$ level for the first and second portfolios are -44 and -38 , respectively. Therefore, the second portfolio is riskier than the first portfolio as expected ( -38 is higher than -44$)$. This is the reason why the "negative" of the mean of portfolio yields that are lower than some percentile is used. 
Similar to the results of the mean-variance analysis, Greer produces the highest simulated yield with the highest ES (Table 5). This point corresponds to the highest point on the mean-ES frontier (Figure 3). At the low to intermediate levels of portfolio ES, it is optimal to allocate more than $60 \%$ of total acres to Duster. At the intermediate to high levels of portfolio ES, producers should plant more than $50 \%$ of Greer. The results are not unexpected, because both Duster and Greer produce relatively high yields over time (Figure 1). Even though the average yield of Duster is lower than that of Greer (56.55 vs. 58.22 bushels per acre), the historical minimum yield of Duster is higher than that of Greer $(48.18$ vs. 43.72 bushels per acre). This makes Duster relatively less risky from the perspective of downside risk framework. Thus, if wheat producers are more risk averse, more acres should be allocated to Duster. Again, even though it seems like the mean-ES approach could help improving in-sample farm productivity, the true performance of the strategy is still unclear.

\subsection{Potential Gains from Portfolio Optimizations}

As mentioned previously, the present study addresses a shortcoming of the previous studies in evaluating the performance of the optimization models. Previously, the performance of the models was evaluated on the period over which the model is estimated (i.e., the optimization or in-sample period). As an illustration, Barkley, Peterson, and Shroyer (2010) used data on wheat variety yields for the period 1993-2006 to derive optimal land allocation strategies based on the mean-variance optimization model. They then compared the average yield of a portfolio constructed using the actual 2006 allocation of varieties planted with that of a portfolio on the efficient frontier with the same level of variance. In practice, however, wheat producers must make decisions regarding which varieties to be planted for the year 2006 before the 2006 yield data exist. Therefore, to better evaluate the performance of optimization models, we instead look at how well the portfolio optimization strategies perform the year after the estimation period.

For comparison purposes, a potential portfolio is constructed for each portfolio optimization model by holding the risk constant at the 2014 actual level. That is, the potential portfolio for the mean-variance model is derived by maximizing the in-sample portfolio yield, subjected to the in-sample variance being equal to that computed using the 2014 actual allocation. Similarly, the potential portfolio for the mean-ES model (at the $10 \%, 5 \%$, and $1 \%$ levels) is constructed by maximizing the in-sample portfolio yield, given that the insample ES (at the $10 \%, 5 \%$, and $1 \%$ levels) is equal to that computed using the 2014 actual allocation and the estimated multivariate probability distribution. Table 6 reports the optimal allocations (the percentage of each variety to be planted) for the four potential portfolios and the percent difference from the 2014 actual wheat variety allocation. The mean-variance and mean-ES models suggest that the wheat producers should stop planting Coronado, TAM 111, 
Table 6. Comparison of the 2014 Actual Allocation versus Optimal Allocations Suggested by the Various Optimization Models

\begin{tabular}{|c|c|c|c|c|c|c|c|c|c|c|}
\hline \multirow[b]{2}{*}{ Models } & \multicolumn{10}{|c|}{ Optimal Allocations Suggested by the Various Optimization Models (\%) } \\
\hline & Coronado & Duster & Fannin & Greer & Jackpot & TAM 111 & TAM 112 & TAM 304 & TAM 401 & TAM W101 \\
\hline Mean-variance model & 0.00 & 25.78 & 2.79 & 9.58 & 8.15 & 0.00 & 0.00 & 53.70 & 0.00 & 0.00 \\
\hline Mean-ES model $(10 \%)$ & 0.00 & 31.05 & 0.00 & 68.95 & 0.00 & 0.00 & 0.00 & 0.00 & 0.00 & 0.00 \\
\hline Mean-ES model $(5 \%)$ & 0.00 & 29.56 & 0.00 & 70.44 & 0.00 & 0.00 & 0.00 & 0.00 & 0.00 & 0.00 \\
\hline \multirow[t]{2}{*}{ Mean-ES model ( $1 \%)$} & 0.00 & 28.38 & 0.00 & 71.62 & 0.00 & 0.00 & 0.00 & 0.00 & 0.00 & 0.00 \\
\hline & \multicolumn{10}{|c|}{ Difference from the 2014 Actual Wheat Variety Allocation (\%) } \\
\hline Mean-variance model & -5.24 & 17.54 & -36.54 & 2.47 & 7.40 & -3.00 & 0.00 & 19.62 & -2.25 & 0.00 \\
\hline Mean-ES model $(10 \%)$ & -5.24 & 22.81 & -39.33 & 61.83 & -0.75 & -3.00 & 0.00 & -34.08 & -2.25 & 0.00 \\
\hline Mean-ES model $(5 \%)$ & -5.24 & 21.32 & -39.33 & 63.32 & -0.75 & -3.00 & 0.00 & -34.08 & -2.25 & 0.00 \\
\hline Mean-ES model (1\%) & -5.24 & 20.14 & -39.33 & 64.50 & -0.75 & -3.00 & 0.00 & -34.08 & -2.25 & 0.00 \\
\hline
\end{tabular}

Notes: The mean-variance model is solved by maximizing the in-sample portfolio yield, given that the in-sample variance is equal to that computed from the 2014 actual allocation. The mean-expected shortfall (ES) models $(10 \%, 5 \%$, and $1 \%)$ are solved by maximizing the in-sample portfolio yield, given that the in-sample ES $(10 \%, 5 \%$, and $1 \%$, respectively) is equal to that computed from the 2014 actual allocation and the estimated multivariate probability distribution. 
and TAM 401. Recall from Table 2 that for the 2014 actual practice, a large proportion of land is allocated to planting Fannin and TAM 304, even though the two varieties are highly correlated (their correlation is 0.84 ). The mean-variance model, however, indicates that the wheat producers should allocate a majority of land acres to planting TAM 304 and Duster, which are much less correlated (their correlation is 0.29). Interestingly, the mean-ES models tell us that, given the 2014 actual downside risk level, the wheat producers diversify too much and that only Duster and Greer should be planted. This is not totally unexpected, because the other varieties (except TAM 304) produce lower yields than Duster and Greer for almost every year and thus do not offer much benefit in term of downside risk protection.

To examine potential gains (losses) from applying the various portfolio optimization methods, the wheat variety yield data for the year 2014 (Table 2) are used to compute the 2014 yield per acre from planting according to the 2014 actual allocation and according to the four potential portfolios. Table 7 reports the 2014 yield and gross profit per acre for the different allocations. The 2014 gross profit per acre is calculated using the 2014 yield per acre and the 2014 market price of wheat in Texas ( $\$ 6.40$ per bushel). ${ }^{15}$ Two observations regarding the performance of the mean-variance and mean-ES approaches can be drawn from Table 7. First, at least for the year 2014, implementing the mean-variance optimization approach would not help wheat producers increase their profits. More specifically, the mean-variance portfolio produces less gross profit than the 2014 actual allocation by approximately $\$ 1.01$ per acre. Second, the mean-ES portfolios (at the $10 \%, 5 \%$, and $1 \%$ ) generate higher gross profit than does the 2014 actual allocation. The highest (lowest) additional gross profit of $\$ 17.31$ (\$16.41) per acre could be obtained by implementing the mean-ES approach at the $1 \%(10 \%)$ level. At the 2014 wheat planted acres for Texas Blacklands $(600,000$ acres $),{ }^{16}$ there could be an approximate gain in gross profit of at least $\$ 9.85$ million to wheat producers in Texas Blacklands. Thus, it seems that varietal diversification based on the downside risk framework is more efficient than the traditional mean-variance method in term of wheat variety selection. One possible explanation for the better performance of the mean-ES model over the mean-variance model is that the former does not prevent the producers from upside gains. Another possible reason is that the mean-ES model is optimized based on simulated yields instead of historical yields. That is, the mean-ES takes into consideration the stochastic nature of wheat variety yields and, thus, is more suitable for the problem of wheat variety selection.

15 The 2014 market price of wheat in Texas is obtained from USDA-NASS (2015).

16 The 2014 wheat planted acres for Texas Blacklands is obtained from USDA-NASS (2015). 
Table 7. Potential Gains from Using Portfolio Optimization Models

\begin{tabular}{|c|c|c|c|c|c|c|c|}
\hline & $\begin{array}{l}\text { Historical } \\
\text { Yield } \\
\text { Standard } \\
\text { Deviation }\end{array}$ & $\begin{array}{l}\text { Simulated } \\
\text { Yield ES } \\
(10 \%)\end{array}$ & $\begin{array}{l}\text { Simulated } \\
\text { Yield ES } \\
(5 \%)\end{array}$ & $\begin{array}{l}\text { Simulated } \\
\text { Yield ES } \\
(1 \%)\end{array}$ & $\begin{array}{l}2014 \text { Yield } \\
\text { per Acre }\end{array}$ & $\begin{array}{l}2014 \text { Gross } \\
\text { Profit per } \\
\text { Acre }\end{array}$ & $\begin{array}{l}\text { Additional Gross } \\
\text { Profit per Acre from } \\
\text { Portfolio Optimization }\end{array}$ \\
\hline 2014 Actual allocation & 4.17 & -45.32 & -45.11 & -45.00 & 61.28 & $\$ 392.21$ & \\
\hline Mean-variance model & 4.17 & -47.43 & -47.14 & -47.06 & 61.12 & $\$ 391.19$ & $\$-1.01$ \\
\hline Mean-ES model $(10 \%)$ & 6.34 & -45.32 & -45.17 & -45.12 & 63.85 & $\$ 408.62$ & $\$ 16.41$ \\
\hline Mean-ES model $(5 \%)$ & 6.39 & -45.25 & -45.11 & -45.06 & 63.93 & $\$ 409.12$ & $\$ 16.91$ \\
\hline Mean-ES model (1\%) & 6.43 & -45.19 & -45.05 & -45.00 & 63.99 & $\$ 409.52$ & $\$ 17.31$ \\
\hline
\end{tabular}

Notes: The mean-variance model is solved by maximizing the in-sample portfolio yield, given that the in-sample variance is equal to that computed from the 2014 actual allocation. The mean-expected shortfall (ES) models (10\%, $5 \%$, and $1 \%)$ are solved by maximizing the in-sample portfolio yield, given that the in-sample ES $(10 \%, 5 \%$, and $1 \%$, respectively) is equal to that computed from the 2014 actual allocation and the estimated multivariate probability distribution. For comparison purposes, historical yield variances for different wheat variety allocations are computed from the historical data, whereas the simulated yield ESs are calculated from the estimated multivariate probability distribution. The 2014 market price of wheat in Texas is $\$ 6.40$ per bushel (U.S. Department of Agriculture, National Agricultural Statistics Service, 2015). The 2014 gross profit per acre is computed using the 2014 actual yields per acre (not in-sample yields per acre). 


\section{Conclusions}

Among the various risk management strategies or tools (including geographic diversification, enterprise diversification, crop diversification, crop insurance, and derivative instruments), wheat varietal diversification can be the most costeffective method for wheat producers to mitigate yield risk caused by diverse growing conditions and unpredictable climate. To determine the optimal mix of wheat varieties, previous studies suggested the adoption of the mean-variance portfolio optimization theory. One major drawback of the mean-variance approach is that it uses variance as the risk measure. However, variance is a correct risk measure only if the distribution of wheat variety yields is multivariate normal, but in reality, crop yields have been found to be nonnormally distributed. To correct this problem, portfolio optimization based on ES has been proposed. However, to the best of our knowledge, such an optimization method has not been applied to the problem of wheat variety selection. This study, therefore, extends the literature in wheat variety selection by comparing the performance of the mean-variance and mean-ES approaches. Such a comparison provides useful insights for designing optimal mixes of wheat varieties to plant. The mean-ES models at the $10 \%, 5 \%$, and $1 \%$ levels are considered for the analysis.

Given the data on Texas Wheat Variety Trial results from 2008 to 2014 (Texas A\&M AgriLife Extension Service, Texas A\&M AgriLife Research, and AgriPro Wheat, 2008, 2009, 2010; Texas A\&M AgriLife Extension Service, Texas A\&M AgriLife Research, and Syngenta Wheat, 2011, 2012, 2013, 2014) for 10 wheat varieties planted in Texas Blacklands, we estimate the optimal mean-variance and mean-ES portfolios using the data from 2008 to 2013. The location is chosen based on data availability and the lack of previous research. The data for the year 2014 are set aside for evaluating the performance of the models. This is an improvement from the previous related studies in which the performance of the optimization models is evaluated on the period over which the model is estimated (i.e., the optimization or in-sample period). Specifically, this study looks at how well the models perform the year after the estimation period. This is a better way to evaluate the performance of optimization strategies because, in reality, wheat producers must make decisions about which varieties to be planted for the year 2014 before the 2014 yield data exist.

For the mean-ES model, we apply a kernel-based Monte Carlo simulation method to calculate ES. Specifically, we use the MVKDE procedure proposed by Richardson, Lien, and Hardaker (2006) to smooth out irregularities in the sparse (limited) data and fit a multivariate probability distribution. The MVKDE method allows us to deal with sparse data and to depart from the multivariate normality assumption.

To evaluate the model performance, we construct a potential portfolio for each portfolio optimization model by holding the risk (variance or ES at the various levels) constant at the 2014 actual allocation level (which is defined 
as the percentage of total wheat acreage in Texas Blacklands planted with the 10 wheat varieties in 2014). We find that, at least for the planting year 2014, the mean-variance strategy produces less gross profit than does the 2014 actual allocation by approximately $\$ 1.01$ per acre. On the other hand, the mean-ES strategies (at the $10 \%, 5 \%$, and $1 \%$ levels) generate higher 2014 gross profit than the 2014 actual allocation. Specifically, additional gross profits of $\$ 16.41$, $\$ 16.91$, and $\$ 17.31$ per acre could be obtained by using the mean-ES strategies at the $10 \%, 5 \%$, and $1 \%$ levels, respectively. At the 2014 wheat planted acres for Texas Blacklands (600,000 acres), this corresponds to an approximate gain in gross profit of at least $\$ 9.85$ million to wheat producers in Texas Blacklands.

Based on our results, the mean-variance model does not perform very well compared with the 2014 actual allocation, and the mean-ES model is a better tool for wheat producers to improve their choice of wheat varieties. Two possible explanations for the better performance of the mean-ES model over the meanvariance model are that the former (1) does not punish the upside gains and (2) takes into consideration the stochastic nature of wheat variety yields in the problem of wheat variety selection. However, given the shortness of relevant historical data, we are able to evaluate the performance of the models only over a 1-year period. Nevertheless, our results suggest that the mean-variance model may not be the best tool for choosing the optimal mix of wheat varieties to plant as suggested by the previous studies, and that portfolio optimization in a downside risk framework seems to be a better alternative. This research is crucial for agricultural producers who aim at improving variety selection and developing a new adaptation strategy to cope with the changing climate.

\section{References}

Artzner, P., F. Delbaen, J.-M. Eber, and D. Heath. "Coherent Measures of Risk." Mathematical Finance 9,3(July 1999):203-28.

Atwood, J., S. Shaik, and M. Watts. "Are Crop Yields Normally Distributed? A Reexamination." American Journal of Agricultural Economics 85,4(2003):888-901.

Barkley, A., H.H. Peterson, and J. Shroyer. "Wheat Variety Selection to Maximize Returns and Minimize Risk: An Application of Portfolio Theory." Journal of Agricultural and Applied Economics 42,1(February 2010):39-55.

Barry, P.J., and P.N. Ellinger. Financial Management in Agriculture. 7th ed. Upper Saddle River, NJ: Prentice Hall, 2012.

Boggess, W.G., K.A. Anaman, and G.D. Hanson. "Importance, Causes, and Management Responses to Farm Risks: Evidence from Florida and Alabama." Southern Journal of Agricultural Economics 17,2(December 1985):105-16.

Bradshaw, B., H. Dolan, and B. Smit. "Farm-Level Adaptation to Climatic Variability and Change: Crop Diversification in the Canadian Prairies." Climatic Change 67,1(November 2004):119-41.

Brennan, J.P. "Measuring the Contribution of New Varieties to Increasing Wheat Yields." Review of Marketing and Agricultural Economics 52,3(December 1984):175-95. 
Day, R.H. "Probability Distributions of Field Crop Yields." Journal of Farm Economics 47,3(August 1965):713-41.

Gallagher, P. "U.S. Soybean Yields: Estimation and Forecasting with Nonsymmetric Disturbances." American Journal of Agricultural Economics 69,4(November 1987):796-803.

Gourdji, S.M., K.L. Mathews, M. Reynolds, J. Crossa, and D.B. Lobell. “An Assessment of Wheat Yield Sensitivity and Breeding Gains in Hot Environments." Proceedings of the Royal Society B 280,1752(February 2013):20122190.

Johnson, R.A., and D.W. Wichern. Applied Multivariate Statistical Analysis. 5th ed. Upper Saddle River, NJ: Prentice Hall, 2002.

Knutson, R.D., E.G. Smith, D.P. Anderson, and J.W. Richardson. "Southern Farmers' Exposure to Income Risk under the 1996 Farm Bill.” Journal of Agricultural and Applied Economics 30,1(July 1998):35-46.

Larsen, R., D. Leatham, and K. Sukcharoen. "Geographical Diversification in Wheat Farming: A Copula-Based CVaR Framework.” Agricultural Finance Review 75,3(2015):368-84.

Lien, G., J.B. Hardaker, M.A.P.M. van Asseldonk, and J.W. Richardson. "Risk Programming Analysis with Imperfect Information." Annals of Operations Research 190,1(October 2011):311-23.

__. "Risk Programming and Sparse Data: How to Get More Reliable Results." Agricultural Systems 101,1-2(June 2009):42-48.

Lobell, D.B., A. Sibley, and J.I. Ortiz-Monasterio. "Extreme Heat Effects on Wheat Senescence in India." Nature Climate Change 2(2012):186-89.

Markowitz, H. "Portfolio Selection.” Journal of Finance 7,1(March 1952):77-91.

Mausser, H., and D. Rosen. "Beyond VaR: From Measuring Risk to Managing Risk.” ALGO Research Quarterly 1,2(December 1998):5-20.

Mortenson, R., J. Parsons, D.L. Pendell, and S.D. Haley. "Wheat Variety Selection: An Application of Portfolio Theory in Colorado." Western Economics Forum 11(2012):10-21.

Nalley, L.L., and A.P. Barkley. "Using Portfolio Theory to Enhance Wheat Yield Stability in Low-Income Nations: An Application in the Yaqui Valley of Northwestern Mexico." Journal of Agricultural and Resource Economics 35,2(August 2010):334-47.

Nalley, L.L., A. Barkley, B. Watkins, and J. Hignight. "Enhancing Farm Profitability through Portfolio Analysis: The Case of Spatial Rice Variety Selection.” Journal of Agricultural and Applied Economics 41,3(December 2009):641-52.

Park, S.C., J. Cho, S.J. Bevers, S. Amosson, and J.C. Rudd. "Dryland Wheat Variety Selection in the Texas High Plain." Paper presented at the Southern Agricultural Economics Association Annual Meeting, Birmingham, Alabama, February 4-7, 2012.

Ramirez, O.A., S. Misra, and J. Field. “Crop-Yield Distributions Revisited.” American Journal of Agricultural Economics 85,1(February 2003):108-20.

Ribera, L.A., J.L. Outlaw, J.W. Richardson, J. Da Silva, and H. Bryant. "Mitigating the Fuel and Feed Effects of Increased Ethanol Production Utilizing Sugarcane.” Paper presented at Biofuels, Food \& Feed Tradeoffs Conference, St. Louis, Missouri, April 12-13, 2007.

Richardson, J.W., S.L. Klose, and A.W. Gray. "An Applied Procedure for Estimating and Simulating Multivariate Empirical (MVE) Probability Distributions in Farm-Level Risk Assessment and Policy Analysis." Journal of Agricultural and Applied Economics 32,2(August 2000):299-315.

Richardson, J.W., G. Lien, and J.B. Hardaker. "Simulating Multivariate Distributions with Sparse Data: A Kernel Density Smoothing Procedure.” Poster paper presented at the 
International Association of Agricultural Economists Conference, Gold Cost, Australia, August 12-18, 2006.

Rockafellar, R.T., and S. Uryasev. "Optimization of Conditional Value-at-Risk.” Journal of Risk 2,3(2000):21-41.

Sonka, S.T., and G.F. Patrick. "Risk Management and Decision Making in Agricultural Firms." Risk Management in Agriculture. P.J. Barry, ed. Ames: Iowa State University Press, 1984.

Strauss, F., S. Fuss, J. Szolgayová, and E. Schmid. "Integrated Assessment of Crop Management Portfolios in Adapting to Climate Change in the Marchfeld Region." Journal of the Austrian Society of Agricultural Economics 19,2(2009):11-20.

Tack, J., A. Barkley, and L.L. Nalley. "Effect of Warming Temperatures on US Wheat Yields." Proceedings of the National Academy of Sciences of the United States of America 112,22(June 2015a):6931-36.

—. "Estimating Yield Gaps with Limited Data: An Application to United States Wheat." American Journal of Agricultural Economics 97,5(October 2015b):1464-77.

"Heterogeneous Effects of Warming and Drought on Selected Wheat Variety Yields." Climatic Change 125,3(August 2014):489-500.

Tack, J., A. Barkley, T.W. Rife, J.A. Poland, and L.L. Nalley. "Quantifying Variety-Specific Heat Resistance and the Potential for Adaptation to Climate Change." Global Change Biology (2015). doi:10.1111/gcb.13163.

Texas A\&M AgriLife Extension Service, Texas A\&M AgriLife Research, and AgriPro Wheat. Blacklands - 2008 Uniform Wheat Variety Trials. Texas A\&M University, 2008. Internet site: http://varietytesting.tamu.edu/wheat/docs/2008/Blackland\%20Pub08.pdf (Accessed March 31, 2016).

- 2009 Texas Wheat Variety Results. Texas A\&M University, 2009. Internet site: http://varietytesting.tamu.edu/wheat/docs/2009/2009\%20Wheat $\% 20$ Variety $\%$ 20Trials.pdf (Accessed March 31, 2016).

- 2010 Texas Wheat Variety Results. Texas A\&M University, 2010. Internet site: http://varietytesting.tamu.edu/wheat/docs/2010/Wheat\%20Binder.pdf (Accessed March 31, 2016).

Texas A\&M AgriLife Extension Service, Texas A\&M AgriLife Research, and Syngenta Wheat. 2011 Texas Wheat Variety Trial Results. Texas A\&M University, 2011. Internet site: http://varietytesting.tamu.edu/wheat/docs/2011/2011\%20Wheat.pdf (Accessed March $31,2016)$.

- 2012 Texas Wheat Variety Trial Results. Texas A\&M University, 2012. Internet site: http://varietytesting.tamu.edu/wheat/docs/2012/2012\%20Wheat\%20Pub.pdf (Accessed March 31, 2016).

- 2013 Texas Wheat Variety Trial Results. Texas A\&M University, 2013. Internet site: http://varietytesting.tamu.edu/wheat/docs/2013/2013\%20Texas\%20Wheat $\%$ 20Variety\%20Trials.pdf (Accessed March 31, 2016).

—. 2014 Texas Wheat Variety Trial Results. Texas A\&M University, 2014. Internet site: http://varietytesting.tamu.edu/wheat/docs/2014/2014\%20Final\%20Wheat $\%$ 20Pub.pdf (Accessed March 31, 2016).

Texas Cooperative Extension and Texas Agricultural Experiment Station. Blacklands 2004-05 Wheat Variety Trials. Texas A\&M University, 2005. Internet site: http://varietytesting.tamu.edu/wheat/docs/Blacklands\%20Wheat $\% 20$ Variety $\%$ 20Trial\%20v1-2005.pdf (Accessed March 31, 2016). 
- Blacklands - 2006 Uniform Wheat Variety Trials. Texas A\&M University, 2006. Internet site: http://varietytesting.tamu.edu/wheat/docs/2006/UWVT06-BL.pdf (Accessed March 31, 2016).

- Blacklands - 2007 Uniform Wheat Variety Trials. Texas A\&M University, 2007. Internet site: http://varietytesting.tamu.edu/wheat/docs/2007/UWVT07-BLcs.pdf (Accessed March 31, 2016).

Tubiello, F.N., C. Rosenzweig, R.A. Goldberg, S. Jagtap, and J.W. Jones. "Effects of Climate Change on US Crop Production: Simulation Results Using Two Different GCM Scenarios. Part I: Wheat, Potato, Maize, and Citrus.” Climate Research 20(2002):259_ 70 .

U.S. Department of Agriculture, National Agricultural Statistics Service (USDA-NASS). Percent of Wheat Acres Seeded for 2014. Internet site: http://www.nass.usda.gov/ Statistics_by_State/Texas/Publications/wheat_seeded_2014.pdf (Accessed April 30, 2015).

Zylstra, M.J., R.L. Kilmer, and S. Uryasev. "Risk Balancing Strategies in the Florida Dairy Industry: An Application of Conditional Value at Risk.” Paper presented at the American Agricultural Economics Association 2003 Annual Meeting, Montreal, Canada, July 27-30, 2003. 